\title{
Role of Personal Protective Measures in Prevention of COVID-19 Spread Among Physicians in Bangladesh: a Multicenter Cross-Sectional Comparative Study
}

\author{
Md. Musab Khalil ${ }^{1}$ (D) $\cdot$ Md Mashiul Alam ${ }^{2}$ (D) Mostafa Kamal Arefin $^{3} \cdot$ Mamunur Rashid Chowdhury $^{4}$. \\ Muhammad Rezeul Huq ${ }^{5}$. Joybaer Anam Chowdhury ${ }^{6}$. Ahad Mahmud Khan ${ }^{7}$
}

Accepted: 20 August 2020 / Published online: 28 August 2020

(C) The Author(s) 2020

\begin{abstract}
This study aims to determine the role of personal protective measures in the prevention of COVID-19 spread among the physicians working at different health facilities in Bangladesh. This hospital-based cross-sectional comparative study was conducted from May to June 2020. A total of 98 COVID-19 positive physicians and 92 COVID-19 negative physicians (physicians with no symptoms of COVID-19 or who tested negative) were enrolled. The questionnaire was adapted from a tool developed by the World Health Organization (WHO) for risk assessment and management of exposure of healthcare workers in the context of COVID-19. Data were collected from the respondents online using Google forms. There was no significant difference in baseline information between COVID-19 positive and COVID-19 negative physicians. The physicians, who were unaware of direct participation in COVID-19 patient care, had higher odds of being COVID-19 positive (OR =4.018; CI: 1.532-10.535). Additionally, the physicians, who were unaware of the COVID-19 status while performing the aerosol-generated procedure (AGP), had a higher chance of being COVID-19 positive ( $\mathrm{OR}=2.522$; CI: $1.020-6.233)$. Using face shields/goggles $(\mathrm{OR}=0.437$; CI:0.228-0.837) and regular decontamination of the patient's surroundings $(\mathrm{OR}=0.392$; CI:0.176-0.873) while usual take care of patients and use of N95 masks while performing AGP $(\mathrm{OR}=0.372$; CI:0.159-0.873) had protective roles against COVID-19 among the physicians. The physicians who had reused the medical gown had two times more chances of being tested positive for COVID-19 than those who had not reused it ( $\mathrm{OR}=2.3 ; \mathrm{CI}: 1.251-4.259)$. The use of face shields/goggles and N95 masks and decontamination of the patient's surroundings may give protection against COVID-19. Additionally, reusing medical gowns should be avoided as much as possible.
\end{abstract}

Keywords COVID-19 $\cdot$ Risk factors $\cdot$ Personal protective equipment $\cdot$ Healthcare workers $\cdot$ Physicians $\cdot$ Bangladesh

This article is part of the Topical Collection on COVID-19

Ahad Mahmud Khan

ahad_mahmud@hotmail.com; A.M.Khan@sms.ed.ac.uk

1 Sheikh Russel National Gastroliver Institute and Hospital, Dhaka, Bangladesh

2 Department of Cardiovascular Disease, Mayo Clinic, Rochester, MN, USA

3 Department of ENT \& Head Neck Surgery, Dhaka Medical College, Dhaka, Bangladesh

4 Department of Pediatric Ophthalmology \& Strabismus, Ispahani Islamia Eye Institute and Hospital, Dhaka, Bangladesh

5 Department of Clinical Neurology, National Institute of Neurosciences and Hospital, Dhaka, Bangladesh

6 National Institute of Cardiovascular Diseases, Dhaka, Bangladesh

7 Usher Institute, The University of Edinburgh, Edinburgh, UK

\section{Introduction}

Coronavirus disease 2019 (COVID-19) has already affected millions of people with more than half-a-million deaths worldwide since the advent of SARS-CoV-2 in late 2019. Although some countries, e.g., China, Singapore, and South Korea, are forerunners to win this run against this deadly virus, this pandemic is still a high-level concern in most countries across the globe. At present, the infection rate and death toll are on the rise among South-Asian countries such as Bangladesh, India, and others [1]. Bangladesh has counted more than two hundred thousand infected people, along with numerous deaths [1,2].

Health professionals are more vulnerable to COVID-19 than any other professionals as they have to work close to the patients [3]. The risk is higher among healthcare workers $(\mathrm{HCWs})$ who are involved in the aerosol-generating procedure (AGP), such as noninvasive ventilation (NIV), high flow nasal 
cannula (HFNC), and endotracheal intubation [4]. HCWs may become a point of source to other non-COVID patients if they cannot be adequately contained.

Researchers in China reported 3387 infections among HCWs, which was $4.4 \%$ of all cases with 23 deaths [5]. According to the Italian National Institute of Health, approximately $17,000 \mathrm{HCWs}$ were infected, which was $10 \%$ of Italy's total cases [6]. Centers for Disease Control (CDC), in the USA, reported that more than $9200 \mathrm{HCWs}$ were caught up with COVID-19 by April 2020 [7]. There is still no precise data about how many HCWs are infected with COVID-19 in Bangladesh. From a reliable source, it can be stipulated that as of July 18, 2020, about 3164 HCWs were affected [8].

Recent evidence shows that even asymptomatic persons can transmit COVID-19 with high efficiency, where conventional measures of protection such as face masks are insufficient $[9$, 10]. This virus may have an affinity to non-respiratory mucosal surfaces such as conjunctiva, which further limits the usefulness of face mask alone [11]. Another study showed that not only subclinical patients spread this virus, but also a person who had already recovered from acute illness can also shed a high amount of virus and thereby infect others [12]. This information warrants aggressive measures such as N95 masks, goggles/face shields, and protective gowns to ensure the safety of HCWs during patient care. Even with appropriate personal protective gear and proper hygiene, COVID-19 infection may occur [13]. HCWs had been forced to work without personal protective equipment (PPE), and legal actions had been taken against them for delaying to attend the patient due to a shortage of PPE [14]. The risk of transmission among healthcare professionals can be mitigated with appropriate precautions in health facilities [15-18]. Establishment of a clearer "zones of risk" and related protective measures can limit transmission in hospitals facing a limited supply of PPE [19].

In Bangladesh, physicians working in hospitals play a significant role in dealing with COVID-19 patients. A substantial number of physicians have already been diagnosed with COVID-19. Approximately 1200 physicians were infected, and 36 lost their lives [20]. It is time to take appropriate measures to prevent the spread of this grave disease among medical staff, especially among physicians. To better understand how to protect the physicians, we investigated the role of personal protective measures or PPE use in the prevention of COVID-19 spread among the physicians working at different health facilities in Bangladesh.

\section{Methods}

\section{Study Design and Setting}

A multicenter comparative cross-sectional study was conducted from May to June 2020 in different hospitals in
Bangladesh. Some hospitals in Bangladesh were specialized for the treatment of COVID-19 positive patients only and were referred to COVID-dedicated hospitals. Suspected COVID-19 patients were referred from other hospitals to COVID-dedicated hospitals. However, sometimes nonCOVID hospitals provided treatment to COVID-positive patients without knowing the COVID status of the patients.

\section{Study Participants}

We collected the list of physicians from different hospitals whose reverse transcriptase-polymerase chain reaction (RTPCR) test was positive. The controls were COVID-19 negative (having no symptoms of COVID-19 or tested negative) who worked in the same hospitals. In our study, we enrolled a total of 98 COVID-19 positive physicians and 92 COVID-19 negative physicians who work in different healthcare facilities and had known or unknown interactions with COVID-19 patients.

\section{Sampling Technique}

First, we approached all COVID-19 positive physicians of the different hospitals for enrollment as per our list. We contacted the COVID-19 negative physicians and enrolled a nearly equal number of physicians from the same hospital.

\section{Data Collection}

We used a predesigned structured questionnaire typed to collect data. It was divided into five sections: (i) physician's information, (ii) physician's interactions with COVID-19 patient, (iii) physician's activities performed on COVID-19 in the healthcare facility, (iv) adherence to infection prevention and control (IPC) procedures during healthcare interactions, and (v) adherence to IPC measures when performing AGP. The questionnaire was adapted from a tool developed by the World Health Organization (WHO) for risk assessment and management of exposure of healthcare workers in the context of COVID-19. The WHO tool has four options to quantify the frequency with which the physicians had taken personal protective measures: "Always" means more than $95 \%$ of the time; "Most of the time" means 50 to under 95\%; "occasionally" means 20 to under 50\%; and "Rarely" means below 20\% [21]. In this study, we considered "Always" or "Most of the time" to define taking proper protective measures for each item. We used Google form to collect data online from the respondents after obtaining consent.

\section{Data Analysis}

We used Statistical Product and Service Solutions (SPSS) version 26 to analyze data. Categorical variables were 
analyzed by the Chi-square test or Fisher's exact test as applicable. A $p$ value of less than 0.05 was considered statistically significant. We also calculated the odds ratio (OR) with $95 \%$ confidence interval (CI) using contingency table and logistic regression where appropriate.

\section{Results}

This study revealed that the mean age of physicians, who were sampled for this study, was $32.7 \pm 5.4$ years, and the age of physicians had no impact on the chance of being COVID-19 positive. Our study shows that physicians working in the ICU/ CCU/OT complex had a slightly increased chance of getting infection, although the difference was not statistically significant $[\mathrm{OR}=1.244, \mathrm{CI}$ : $0.402-3.845)$. Male physicians $(\mathrm{OR}=$ 1.152; CI: 0.590-2.249) and formal training on PPE use $(\mathrm{OR}=1.667$; CI: $0.890-3.121)$ mildly increased the odds of being infected, which was not significant (Table 1).

Table 2 depicts that physicians, who were unaware of any contact with COVID-19 patients, had lower odds of being COVID-19 positive (OR $=0.352$; CI: 0.131-0.945). However, when asked about direct participation in COVID19 patient care, such unawareness shows higher odds (OR = 4.018; CI: $1.532-10.535)$, and this association is statistically significant $(p=0.004)$. Physicians, who were unaware of the
COVID-19 status while performing AGP, also had a higher chance of being COVID-19 positive (OR $=2.522$; CI: 1.020 $6.233)$. On the other hand, direct contact with contaminated fomites had no significant association with COVID-19 positivity.

We calculated the odds ratio of different protective measures taken by the physicians, which might have some role to prevent catching COVID-19 infection during usual patient care or while doing AGP (Tables 3 and 4). Face shields/ goggles and regular decontamination of the patient's surroundings had a protective role during usual patient care $(\mathrm{OR}=0.437$; CI: $0.228-0.837$ and $\mathrm{OR}=0.392$; CI: 0.176 0.873 , respectively). On the other hand, though not statistically significant, wearing PPE and proper handling of PPE might prevent catching this virus $(\mathrm{OR}=0.146$; $\mathrm{CI}$ : $0.018-1.212$ and 0.570; CI: $0.286-1.137$, respectively), while single-use gloves and wearing mask or disposable gown did not have a clear association among COVID-19 positive and COVID-19 negative patients. Proper hand hygiene during different situations while dealing with patients had mixed results, and none of them was statistically significant (Table 3 ).

During AGP in COVID-19 patients, wearing the N95 mask was significantly associated with a low probability of COVID-19 infection (OR = 0.373; CI: 0.159-0.873). In contrast, wearing PPE, single-use gloves, protective face-shields/ goggles, disposable gown, water-proof apron, proper handling
Table 1 Baseline information of the participants

\begin{tabular}{|c|c|c|c|c|}
\hline Traits & $\begin{array}{l}\text { Covid-19 positive } \\
n=98 \\
N(\%)\end{array}$ & $\begin{array}{l}\text { Covid-19 negative } \\
n=92 \\
N(\%)\end{array}$ & $p$ value & OR $(95 \% \mathrm{CI})$ \\
\hline \multicolumn{5}{|l|}{ Age in years } \\
\hline$<35$ & $30(30.6)$ & $21(22.8)$ & \multirow[t]{2}{*}{$0.226^{\mathrm{a}}$} & Reference \\
\hline$\geq 35$ & $68(69.4)$ & $71(77.2)$ & & $0.670[0.350-1.283]$ \\
\hline Mean \pm SD & $32.7 \pm 5.4$ & $32.5 \pm 3.8$ & $0.704^{\mathrm{b}}$ & \\
\hline \multicolumn{5}{|l|}{ Sex } \\
\hline Female & $22(22.4)$ & $23(25.0)$ & \multirow[t]{2}{*}{$0.679^{\mathrm{a}}$} & Reference \\
\hline Male & $76(77.6)$ & $69(75.0)$ & & 1.152 [0.590-2.249] \\
\hline \multicolumn{5}{|l|}{ Working hospital } \\
\hline Outside Dhaka & $17(17.3)$ & $11(12.0)$ & \multirow[t]{2}{*}{$0.295^{\mathrm{a}}$} & Reference \\
\hline Inside Dhaka & $81(82.7)$ & $81(88.0)$ & & $0.647[0.285-1.467]$ \\
\hline \multicolumn{5}{|l|}{ Place of work } \\
\hline Inpatient & $41(41.8)$ & $34(37.0)$ & \multirow[t]{5}{*}{$0.702^{\mathrm{a}}$} & Reference \\
\hline Outpatient/triage & $23(23.5)$ & $30(32.6)$ & & $0.636[0.313-1.291]$ \\
\hline Emergency & $17(17.3)$ & $15(16.3)$ & & $0.940[0.410-2.155]$ \\
\hline ICU/CCU/OT complex & $9(9.2)$ & $6(6.5)$ & & $1.244[0.402-3.845]$ \\
\hline Tertiary care & $8(8.2)$ & $7(7.6)$ & & $0.948[0.312-2.880]$ \\
\hline \multicolumn{5}{|c|}{ Received formal training on PPE use } \\
\hline No & $63(64.3)$ & $69(75.0)$ & \multirow[t]{2}{*}{$0.109^{\mathrm{a}}$} & Reference \\
\hline Yes & $35(35.7)$ & $23(25.0)$ & & $1.667[0.890-3.121]$ \\
\hline
\end{tabular}

${ }^{\mathrm{a}}$ Chi-square test; ${ }^{\mathrm{b}}$ Independent samples $t$ test; ${ }^{\mathrm{c}}$ Fisher's exact test 
Table 2 Exposure of the participants to the COVID-19 patients

\begin{tabular}{|c|c|c|c|c|}
\hline Traits & $\begin{array}{l}\text { Covid-19 positive } \\
n=98 \\
N(\%)\end{array}$ & $\begin{array}{l}\text { Covid-19 negative } \\
n=92 \\
N(\%)\end{array}$ & $p$ value & OR $[95 \% \mathrm{CI}]$ \\
\hline \multicolumn{5}{|l|}{ Contact with COVID-19 patients } \\
\hline Hospital environment & $41(41.8)$ & $35(38.0)$ & $0.113^{\mathrm{c}}$ & Reference \\
\hline $\begin{array}{l}\text { Suspected COVID-19 patient or } \\
\text { health worker }\end{array}$ & $23(23.5)$ & $13(14.1)$ & & $1.510[0.668-3.416]$ \\
\hline $\begin{array}{l}\text { Confirmed COVID-19 patient or } \\
\text { health worker }\end{array}$ & $23(23.5)$ & $24(26.1)$ & & $0.818[0.395-1.695]$ \\
\hline Community source & $4(4.1)$ & $3(3.3)$ & & $1.138[0.238-5.435]$ \\
\hline Unknown & $7(7.1)$ & $17(18.5)$ & & $0.352[0.131-0.945]$ \\
\hline \multicolumn{5}{|c|}{ Participated in direct COVID-19 patient care } \\
\hline No & $32(32.7)$ & $36(39.1)$ & $0.004^{\mathrm{a}}$ & Reference \\
\hline Yes & $41(41.8)$ & $49(53.3)$ & & $0.941[0.501-1.770]$ \\
\hline Unknown & $64(25.5)$ & $7(7.6)$ & & $4.018[1.532-10.535]$ \\
\hline \multicolumn{5}{|c|}{ Performed aerosol-generating procedures on COVID-19 patient } \\
\hline No & $58(59.2)$ & $65(70.7)$ & $0.118^{\mathrm{a}}$ & Reference \\
\hline Yes & $22(22.4)$ & $19(20.7)$ & & $1.298[0.639-2.636]$ \\
\hline Unknown & $18(18.4)$ & $8(8.7)$ & & $2.522[1.020-6.233]$ \\
\hline \multicolumn{5}{|c|}{ Direct contact with contaminated fomites } \\
\hline No & $30(30.6)$ & $40(43.5)$ & $0.185^{\mathrm{a}}$ & Reference \\
\hline Yes & $43(43.9)$ & $33(35.9)$ & & $1.737[0.902-3.347]$ \\
\hline Unknown & $25(25.5)$ & $18(20.7)$ & & $1.754[0.819-3.757]$ \\
\hline
\end{tabular}

${ }^{\mathrm{a}}$ Chi-square test; ${ }^{\mathrm{c}}$ Fisher's exact test

of PPE, proper hand-hygiene during different patient care, and decontamination of the surroundings of the patient decreased the chance of COVID-19 infection among physicians. However, none of these results were statistically significant (Table 4).

As most physicians had to reuse their PPE items, we also investigated the role of reusing PPE items in catching
COVID-19 infection among physicians. Figure 1 shows that more physicians, who were not diagnosed with COVID-19, had reused masks, goggles, and face-shields than physicians who were tested COVID positive. However, these associations were not statistically significant $(p>0.05)$. In addition, physicians who had reused their protective gown had two times more chances to be tested positive in comparison with

Table 3 Protective measures taken by the participants during usual care of COVID-19 patients

\begin{tabular}{|c|c|c|c|c|}
\hline Protective measures & $\begin{array}{l}\text { Covid-19 positive } \\
n=98 \\
N(\%)\end{array}$ & $\begin{array}{l}\text { Covid-19 negative } \\
n=92 \\
N(\%)\end{array}$ & $p$ value & OR $[95 \% \mathrm{CI}]$ \\
\hline Wore PPE $(n=186)$ & $90(92.8)$ & $88(98.9)$ & $0.066^{\mathrm{b}}$ & $0.146[0.018-1.212]$ \\
\hline Single-use gloves $(n=179)$ & $81(90.0)$ & $80(89.9)$ & $0.980^{\mathrm{a}}$ & $1.013[0.382-2.682]$ \\
\hline Medical/surgical mask $(n=181)$ & $89(96.7)$ & $85(95.5)$ & $0.717^{\mathrm{b}}$ & $1.396[0.303-6.423]$ \\
\hline Face-shield/goggles $(n=180)$ & $55(59.8)$ & $68(77.3)$ & $0.012^{\mathrm{a}}$ & $0.437[0.228-0.837]$ \\
\hline Disposable gown $(n=179)$ & $71(78.9)$ & $69(77.5)$ & $0.825^{\mathrm{a}}$ & $1.083[0.533-2.203]$ \\
\hline Proper "doning" and "doffing" of PPE $(n=173)$ & $59(68.6)$ & $69(79.3)$ & $0.109^{\mathrm{a}}$ & $0.570[0.286-1.137]$ \\
\hline $\begin{array}{l}\text { Followed hand hygiene during patient } \\
\text { care }(n=172)\end{array}$ & $78(92.9)$ & $83(94.3)$ & $0.695^{\mathrm{a}}$ & $0.783[0.230-2.670]$ \\
\hline Followed HH during procedure $(n=164)$ & $75(97.4)$ & $80(92.0)$ & $0.175^{\mathrm{b}}$ & $3.281[0.661-16.297]$ \\
\hline Followed HH after body-fluid exposure $(n=154)$ & $67(91.8)$ & $79(97.5)$ & $0.151^{\mathrm{b}}$ & $0.283[0.055-1.447]$ \\
\hline Followed HH after touching fomites $(n=166)$ & $76(93.8)$ & $77(90.6)$ & $0.438^{\mathrm{a}}$ & $1.579[0.494-5.045]$ \\
\hline Decontaminated surroundings $(n=165)$ & $58(72.5)$ & $74(87.1)$ & $0.019^{\mathrm{a}}$ & $0.392[0.176-0.873]$ \\
\hline
\end{tabular}

${ }^{\mathrm{a}}$ Chi-square test; ${ }^{\mathrm{b}}$ Fisher's exact test 
Table 4 Protective measures taken by the participants during the aerosol-generating procedure

\begin{tabular}{|c|c|c|c|c|}
\hline Protective measures & $\begin{array}{l}\text { Covid-19 positive } \\
n=98 \\
N(\%)\end{array}$ & $\begin{array}{l}\text { Covid-19 negative } \\
n=92 \\
N(\%)\end{array}$ & $p$ value & OR $[95 \% \mathrm{CI}]$ \\
\hline Wore PPE $(n=130)$ & $58(92.1)$ & $64(95.5)$ & $0.483^{\mathrm{b}}$ & $0.544[0.124-2.376]$ \\
\hline Single-use gloves $(n=124)$ & $53(93)$ & $64(94.4)$ & $0.702^{\mathrm{b}}$ & $0.621[0.133-2.899]$ \\
\hline N95 Mask $(n=122)$ & $36(65.5)$ & $56(83.6)$ & $0.021^{\mathrm{a}}$ & $0.372[0.159-0.873]$ \\
\hline Face-shield/goggles $(n=122)$ & $39(70.9)$ & $52(77.6)$ & $0.397^{\mathrm{a}}$ & $0.702[0.310-1.593]$ \\
\hline Disposable gown $(n=123)$ & $43(78.2)$ & $56(82.4)$ & $0.562^{\mathrm{a}}$ & $0.768[0.314-1.876]$ \\
\hline Water-proof apron $(n=123)$ & $19(34.5)$ & $35(51.5)$ & $0.060^{\mathrm{a}}$ & $0.498[0.239-1.034]$ \\
\hline Proper "doning" and "doffing" of PPE $(n=126)$ & $41(70.7)$ & $56(82.4)$ & $0.121^{\mathrm{a}}$ & 0.517 [0.223-1.199] \\
\hline Followed Hand Hygiene during patient care $(n=124)$ & $54(93.1)$ & $62(93.9)$ & $0.850^{\mathrm{a}}$ & $0.871[0.208-3.671]$ \\
\hline Followed HH during procedure $(n=122)$ & $51(91.1)$ & $62(93.9)$ & $0.731^{\mathrm{b}}$ & $0.658[0.168-2.579]$ \\
\hline Followed HH after touching fomites $(n=122)$ & $48(85.7)$ & $60(90.9)$ & $0.370^{\mathrm{a}}$ & $0.600[0.195-1.847]$ \\
\hline Decontaminated surroundings $(n=119)$ & $35(62.5)$ & $47(74.6)$ & $0.155^{\mathrm{a}}$ & $0.567[0.259-1.243]$ \\
\hline
\end{tabular}

${ }^{\mathrm{a}}$ Chi-square test; ${ }^{\mathrm{b}}$ Fisher's exact test

physicians who did not reuse their gown $(\mathrm{OR}=2.3$; CI:1.251$4.259 ; p=0.007)$.

\section{Discussion}

Risk factor assessment of COVID-19 among physicians is a timely issue. To date, large numbers of physicians have become infected while treating COVID-19 patients [20]. Bangladesh is one of the worst affected countries in terms of physicians being affected and deceased [22]. This study was conducted to determine the personal protective measurerelated factors responsible for these large numbers of physicians being affected by COVID- 19 .
The mean age of the affected physicians was $32.7 \pm$ 5.4 years. A study conducted on physicians in the USA showed that the median age of physicians being affected was 42 years [7]. Another study conducted in Wuhan, China, revealed that the mean age of the affected physicians was 37 years [23]. From this finding, it seems that the physicians in Bangladesh were affected at a relatively younger age. At Wuhan, relatively older-aged physicians were affected with COVID-19, and the age difference between infected and uninfected physicians was significant [23]. However, in our study, no statistically significant difference was found regarding age between these two groups. We found that male physicians had increased odds of being infected, although this was not statistically significant. This sex difference was not statistically
Fig. 1 Pattern of reused PPE items among the participants

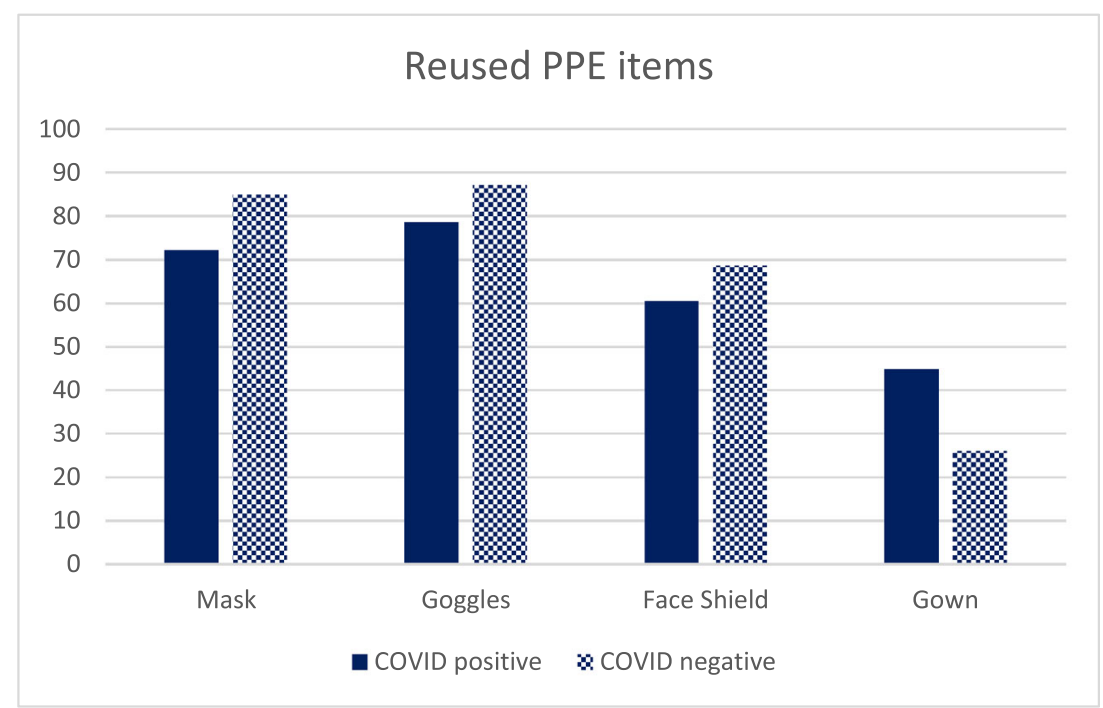

SN Comprehensive Clinical Medicine A SPRINGER NATURE journal 
significant in the study at Wuhan as well [23]. However, female physicians were affected with COVID-19 2.5 times more than their male colleagues in the USA [7].

This study revealed that the chances of becoming infected were higher among patients in the ICU than among inpatients, but the difference was not statistically significant. In contrast, Wuhan's study showed that physicians working in the ICU had two times more chances of becoming infected than the general wards [23]. This difference could be due to the lower number of respondents working in the ICU in our study.

Formal PPE training did not have any significant impact in our study on being infected with COVID-19 or not. None of the physicians from Wuhan contacted COVID-19 infection after being adequately trained about PPE [24]. This contrasting picture in this study could be due to the lack of supervision and monitoring about how to use PPE after the physicians were trained to use PPE.

An interesting finding of our study was that the physicians, who were unaware of any contact with COVID-19 patients or who were unaware of the patient's COVID-19 status during AGP, had a higher chance of being COVID-19 positive. This could be an asymptomatic or pre-symptomatic transmission of the SARS-CoV-2 virus through respiratory droplets [9]. This finding recommends taking appropriate protective measures during direct patient care and performing AGP until the physician is confident that the patient is not suffering from COVID-19, especially in this pandemic situation.

This study revealed that the proper use of face shields or goggles significantly protected the physicians from COVID-19. Using the face shield is also recommended by the WHO, especially during AGP [25]. This study also showed that decontaminated hospital surroundings also significantly increased infection rates among physicians. Lack of control of environmental decontaminants and inadequate infection prevention and control measures might have contributed to the infection. A proper implementation would mitigate this problem [26]. N95 masks provided a protective factor against COVID-19 among those who performed AGP. The WHO also recommends N95 mask use during performing AGP. An interesting finding was that physicians who reused gowns had significantly two times higher chances of becoming infected with COVID 19 than others. This result emphasizes the proper use and adequate supply of PPEs, which are of utmost importance for preventing infections among physicians.

The study had some limitations as well. As the physicians had to recall their events while filling up the questionnaire, there might be a chance of recall bias. Additionally, the sample size was small. We could not include physicians of all age groups. Furthermore, a large-scale study may be helpful to determine the actual reason behind the high rate of infections among physicians in Bangladesh.

\section{Conclusion}

Despite the limitations, this study helped to understand the reasons behind the infection risks of healthcare providers. Proper use of the face shield, adequate decontamination of the patient's surroundings during the usual patient encounter, and wearing the N95 mask and not reusing medical gowns during AGP could be the game changer.

Acknowledgements The authors would like to acknowledge all respected respondents for their valuable time and participation in this research work.

Authors' Contributions MMK, MMA, and AMK formed the idea and developed the design of this study. MMK, MKA, MRH, JAC, and MRC were involved in data collection. AMK and MMA performed the analysis. MMK, MMA, and AMK drafted the manuscript. MMA, AMK, MRH, MRC, MKA, and JAC reviewed the manuscript. All the authors read and approved the final manuscript.

\section{Compliance with Ethical Standards}

Conflict of Interest The authors declare that they have no conflict of interest.

Ethical Approval Ethical approval was obtained from the ethical review committee of Dhaka Medical College. All procedures performed in this study were in accordance with the ethical standards of the institutional and/or national research committee and with the 1964 Helsinki declaration and its later amendments or comparable ethical standards.

Informed consent Informed consent was obtained from each participant.

Open Access This article is licensed under a Creative Commons Attribution 4.0 International License, which permits use, sharing, adaptation, distribution and reproduction in any medium or format, as long as you give appropriate credit to the original author(s) and the source, provide a link to the Creative Commons licence, and indicate if changes were made. The images or other third party material in this article are included in the article's Creative Commons licence, unless indicated otherwise in a credit line to the material. If material is not included in the article's Creative Commons licence and your intended use is not permitted by statutory regulation or exceeds the permitted use, you will need to obtain permission directly from the copyright holder. To view a copy of this licence, visit http://creativecommons.org/licenses/by/4.0/.

\section{References}

1. Worldometer. COVID-19 Coronavirus Pandemic. $2020 \mathrm{https} / /$ www.worldometers.info/coronavirus/. Accessed 18 July 2020.

2. Institute of Epidemiology Disease Control and Research. Covid-19 Status for Bangladesh. 2020 Accessed 18 July 2020.

3. Lai THT, Tang EWH, Chau SKY, Fung KSC, Li KKW. Stepping up infection control measures in ophthalmology during the novel coronavirus outbreak: an experience from Hong Kong. Graefes Arch Clin Exp Ophthalmol. 2020;258(5):1049-55. https://doi.org/ 10.1007/s00417-020-04641-8. 
4. Tran K, Cimon K, Severn M, Pessoa-Silva CL, Conly J. Aerosol generating procedures and risk of transmission of acute respiratory infections to healthcare workers: a systematic review. PLoS One. 2012;7(4):e35797. https://doi.org/10.1371/journal.pone.0035797.

5. Zhan M, Qin Y, Xue X, Zhu S. Death from Covid-19 of 23 health care workers in China. N Engl J Med. 2020;382(23):2267-8. https://doi.org/10.1056/NEJMc2005696.

6. Instituto Superiore di Sanità. Integrated surveillance of COVID-19 in Italy. 2020; https://www.epicentro.iss.it/en/coronavirus/bollettino/ Infografica 17aprile\%20ENG.pdf. Accessed April 282020.

7. Characteristics of health care personnel with COVID-19 - United States, February 12-April 9, 2020 (2020). MMWR Morb Mortal Wkly Rep. 69(15):477-481. https://doi.org/10.15585/mmwr. mm6915e6.

8. Dhaka Tribune. Coronavirus: 3,164 healthcare workers infected in Bangladesh. 2020; https://www.dhakatribune.com/health/ coronavirus/2020/06/13/coronavirus-3-164-healthcare-workersinfected-in-bangladesh. Accessed 18 July 2020.

9. Chang D, Xu H, Rebaza A, Sharma L, Dela Cruz CS. Protecting health-care workers from subclinical coronavirus infection. Lancet Respir Med. 2020;8(3):e13. https://doi.org/10.1016/s22132600(20)30066-7.

10. Chan JF, Yuan S, Kok KH, To KK, Chu H, Yang J, et al. A familial cluster of pneumonia associated with the 2019 novel coronavirus indicating person-to-person transmission: a study of a family cluster. Lancet. 2020;395(10223):514-23. https://doi.org/10.1016/ s0140-6736(20)30154-9.

11. Yan A. Chinese expert who came down with Wuhan coronavirus after saying it was controllable thinks he was infected through his eyes China: South China morning post. 2020.

12. Rothe C, Schunk M, Sothmann P, Bretzel G, Froeschl G, Wallrauch C, et al. Transmission of 2019-nCoV infection from an asymptomatic contact in Germany. N Engl J Med. 2020;382(10):970-1. https://doi.org/10.1056/NEJMc2001468.

13. Godlee F. Protect our healthcare workers. British Medical Journal Publishing Group; 2020.

14. Dyer C. Covid-19: healthcare professional is referred to regulator for delaying seeing a patient because of lack of PPE. Bmj. 2020;370:m3201. https://doi.org/10.1136/bmj.m3201.

15. Ghinai I, McPherson TD, Hunter JC, Kirking HL, Christiansen D, Joshi K, et al. First known person-to-person transmission of severe acute respiratory syndrome coronavirus 2 (SARS-CoV-2) in the USA. Lancet. 2020;395(10230):1137-44. https://doi.org/10.1016/ s0140-6736(20)30607-3.

16. Marchand-Senécal X, Kozak R, Mubareka S, Salt N, Gubbay JB, Eshaghi A, et al. Diagnosis and management of first case of
COVID-19 in Canada: lessons applied from SARS. Clin Infect Dis. 2020. https://doi.org/10.1093/cid/ciaa227.

17. Ni L, Zhou L, Zhou M, Zhao J, Wang DW. Combination of western medicine and Chinese traditional patent medicine in treating a family case of COVID-19. Front Med. 2020;14(2):210-4. https://doi. org/10.1007/s11684-020-0757-x.

18. Cai SJ, Wu LL, Chen DF, Li YX, Liu YJ, Fan YQ, et al. Analysis of bronchoscope-guided tracheal intubation in 12 cases with coronavirus disease 2019 under the personal protective equipment with positive pressure protective hood. Zhonghua Jie $\mathrm{He} \mathrm{He} \mathrm{Hu} \mathrm{Xi} \mathrm{Za}$ Zhi. 2020;43(4):332-4. https://doi.org/10.3760/cma.j.cn11214720200222-00153.

19. De Georgeo MR, De Georgeo JM, Egan TM, Klee KP, Schwemm MS, Bye-Kollbaum H, et al. Containing SARS-CoV-2 in hospitals facing finite PPE, limited testing, and physical space variability: navigating resource constrained enhanced traffic control bundling. J Microbiol Immunol Infect. 2020. https://doi.org/10.1016/j.jmii. 2020.07.009.

20. Arab News. Bangladesh loses doctors to COVID-19. 2020; https:// www.arabnews.com/node/1689996/world. Accessed June 242020

21. World Health Organization. Risk assessment and management of exposure of health care workers in the context of COVID-19: interim guidance, 19 march 2020. World Health Organization; 2020.

22. Prothomalo. COVID-19: Physicians' mortality rate in Bangladesh 'highest in the world'. 2020; https://en.prothomalo.com/ bangladesh/covid-19-physicians-mortality-rate-in-bangladeshhighest-in-the-world. Accessed 19 Jult 2020.

23. Bai Y, Wang X, Huang Q, Wang H, Gurarie D, Ndeffo-Mbah M, Fan F, Fu P, Horn MA, Xu S. SARS-CoV-2 infection in health care workers: a retrospective analysis and a model study. medRxiv. 2020.

24. Liu M, Cheng SZ, Xu KW, Yang Y, Zhu QT, Zhang H, et al. Use of personal protective equipment against coronavirus disease 2019 by healthcare professionals in Wuhan, China: cross sectional study. Bmj. 2020;369:m2195. https://doi.org/10.1136/bmj.m2195.

25. World Health Organization. Rational use of personal protective equipment (PPE) for coronavirus disease (COVID-19): interim guidance, 19 March 2020. World Health Organization; 2020.

26. World Health Organization. Infection prevention and control during health care when novel coronavirus $(\mathrm{nCoV})$ infection is suspected: interim guidance, 25 January 2020.

Publisher's Note Springer Nature remains neutral with regard to jurisdictional claims in published maps and institutional affiliations. 